\title{
Correction to: Neurological update: use of cardiac troponin in patients with stroke
}

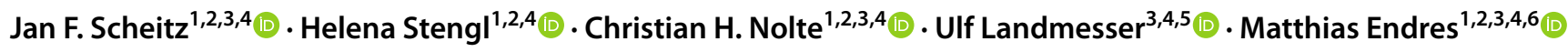

Published online: 25 February 2021

(c) The Author(s) 2021

\section{Correction to: Journal of Neurology https://doi.org/10.1007/s00415-020-10349-w}

The original version of this article unfortunately contained a mistake. Reference [23] has to be deleted.

The original article has been corrected.

Open Access This article is licensed under a Creative Commons Attribution 4.0 International License, which permits use, sharing, adaptation, distribution and reproduction in any medium or format, as long as you give appropriate credit to the original author(s) and the source, provide a link to the Creative Commons licence, and indicate if changes were made. The images or other third party material in this article are included in the article's Creative Commons licence, unless indicated otherwise in a credit line to the material. If material is not included in the article's Creative Commons licence and your intended use is not permitted by statutory regulation or exceeds the permitted use, you will need to obtain permission directly from the copyright holder. To view a copy of this licence, visit http://creativecommons.org/licenses/by/4.0/.

The original article can be found online at https://doi.org/10.1007/ s00415-020-10349-w.

Jan F. Scheitz

jan.scheitz@charite.de

1 Klinik für Neurologie mit Experimenteller Neurologie, Charité-Universitätsmedizin Berlin, Berlin, Germany

2 Center for Stroke Research Berlin, Charité-Universitätsmedizin Berlin, Berlin, Germany

3 German Center for Cardiovascular Research (Deutsches Zentrum Für Herz-Kreislaufforschung; DZHK), partner site Berlin, Berlin, Germany

4 Berlin Institute of Health, Berlin, Germany

5 Department of Cardiology, Charité-Universitätsmedizin Berlin, Campus Benjamin Franklin, 12203 Berlin, Germany

6 German Center for Neurodegenerative Diseases (Deutsches Zentrum Für Neurodegenerative Erkrankungen; DZNE), partner site Berlin, Berlin, Germany 